\title{
SEROSTATUS AND RISK FACTORS OF TICK-BORNE ENCEPHALITIS
}

\author{
Andrea Bušová1, Erik Dorko, Eva Feketeová², Matúš Bereš³ Kvetoslava Rimárová1, Jana Diabelková1, Tímea \\ Rovenská', Róbert Čellár ${ }^{3}$, Tomáš Csank ${ }^{4}$ \\ 1'Department of Public Health and Hygiene, Faculty of Medicine, Pavol Jozef Šafárik University in Košice, Košice, Slovak Republic \\ 2Department of Neurology, Faculty of Medicine, Pavol Jozef Šafárik University in Košice and Louis Pasteur University Hospital, Košice, Slovak \\ Republic \\ ${ }^{3}$ Department of Orthopaedics and Traumatology of Locomotory Apparatus, Faculty of Medicine, Pavol Jozef Šafárik University in Košice and \\ Louis Pasteur University Hospital, Košice, Slovak Republic \\ ${ }^{4}$ Department of Microbiology and Immunology, University of Veterinary Medicine and Pharmacy, Košice, Slovak Republic
}

\begin{abstract}
SUMMARY
Objective: The aim of this seroepidemiological study was to determine the current prevalence of antibodies against tick-borne encephalitis virus (TBEV) in the representative group of Slovak population with included potential risk factors for TBEV.

Methods: Representative group consisted of 428 persons (also with possible exposure to risk factors for tick bite or raw milk consumption). Serum samples were screened by commercial enzyme-linked immunosorbent assay (ELISA). The persons involved in the study completed questionnaires with general demographic, epidemiological and clinical data. During the analysis, we used linear regression to interpret the influence between selected variables.

Results: We detected $1.2 \%$ prevalence of positive $\operatorname{lgG}$ and $1.6 \%$ prevalence of positive lgM antibodies in all tested groups. Our results also confirmed that the following risk factors such as tourism, hunting, fishing, and consumption of raw milk are significantly associated with the prevalence of specific antibodies against TBEV.

Conclusion: The results of seroprevalence obtained by this study confirm the possibility of infection with TBEV among respondents exposed to possible contact with ticks.
\end{abstract}

Key words: tick-borne encephalitis, risk factor, seroprevalence

Address for correspondence: E. Dorko, Department of Public Health and Hygiene, Faculty of Medicine, Pavol Jozef Šafárik University in Košice, Šrobárova 2, 04180 Košice, Slovak Republic. E-mail: erik.dorko@upjs.sk

https://doi.org/10.21101/cejph.a5289

\section{INTRODUCTION}

Tick-borne encephalitis virus (TBEV) is one of the most frequent causes of the central nervous system infections in Europe, especially in endemic areas of Central and Eastern Europe and Russia $(1,2)$. The epidemiology of TBE depends on various factors, such as increased recreational activities in areas infested by ticks, and climatic changes affecting tick habitats and in addition, anthropomorphic changes in agriculture and outdoor and free-time activities, increase the risk that humans will be infected TBE $(2,6)$. The virus can be transmitted by bites of infectious ticks or alimentary infections caused by consumption of raw milk $(3,4)$. Increase in traveling, access to high-risk areas, and the free-time activities within TBE-endemic areas are puts more people at risk of exposition to TBE (5). With the favoured consumption of unpasteurized milk and dairy products of goat, sheep and cow milk in Slovakia, outbreaks of alimentary infection of TBE are common. Therefore, alimentary cases are responsible for almost $23 \%$ of all TBE cases in Slovakia. Food-borne transmission of TBE was first reported in Czechoslovakia in 1954 (9).
This was finded by following the TBE epidemic of 1951 in the east Slovak town of Rožňava where 660 persons were infected. The source of infection was contaminated goat milk which had been mixed into cow milk at the local dairy factory and distributed without pasteurization (10). Human behavior is an important factor and should always be considered in studies of TBE (12).

The main aim of this study was to detect the TBE seroprevalence in a selected group risk group of the population and to confirm the association with the risk factors common for Slovakia.

\section{MATERIALS AND METHODS}

\section{Study Design}

Study Design: Cross-sectional Study. Approval of the study protocol has been approved by the Ethics Committee of the University Hospital of Košice and informed consents were signed by all the participants. 


\section{Data Collection}

Blood samples with questionnaires were collected in eastern Slovakia from July 2014 to December 2016. The group consisted of 428 persons (examined in the Department of Neurology, Department of Dermatovenerology, Department of Orthopedics and Traumatology of Locomotory Apparatus and from Department of Rheumatology without TBE suspection and random persons who should be exposed to ticks from Zlatá Idka, Hrabušice and Jánovce). People involved in this study declared that they had not been vaccinated against tick-borne encephalitis, Japanese encephalitis or yellow fever.

\section{Serum Samples}

The serum was acquired from blood samples by the centrifugation $(2,500 \mathrm{rpm} / 10 \mathrm{~min})$ and stored at $-80{ }^{\circ} \mathrm{C}$ until serological testing. The serum samples were processed in the Laboratory of the Department of Microbiology and Immunology of the University of Veterinary Medicine and Pharmacy in Košice.

\section{Questionnaire}

The questionnaires consist of demographic data (gender, age, residence) and epidemiological data (tick bite, contact with animals, frequent outdoor activities such nature walks, hunting, fishing, tourism and consumption of raw milk).

\section{Laboratory Analysis}

All serological assays were carried out and results were interpreted according to the manufacturers' instructions and the optical density was measured with a spectrophotometer at $450 \mathrm{~nm}$ using an ELISA reader (Synergy HT BioTek). The ELISA test (TBE/ FSME IgG and IgM-ELISA NovaLisa ${ }^{\mathrm{TM}}$, NovaTec, Germany) was applied for general screening of specific TBE antibodies.

Serum IgM levels equal to $11 \mathrm{NTU} / \mathrm{ml}$ and above were considered as positive, those between 9 and $10 \mathrm{NTU} / \mathrm{ml}$ were considered as borderline, and those below $9 \mathrm{NTU} / \mathrm{ml}$ were considered as negative. Serum $\mathrm{IgG}$ levels equal to $110 \mathrm{NTU} / \mathrm{ml}$ and above were considered as positive, those between $55-110 \mathrm{NTU} / \mathrm{ml}$ were borderline, and those below 55 were considered as negative.

Table 1. General characteristics of examined subjects $(N=428)$

\begin{tabular}{|c|c|c|c|c|c|c|c|}
\hline \multirow{3}{*}{\multicolumn{2}{|c|}{ Risk factors/characteristics }} & \multicolumn{6}{|c|}{ Investigated groups } \\
\hline & & \multicolumn{2}{|c|}{ Men } & \multicolumn{2}{|c|}{ Women } & \multicolumn{2}{|c|}{ Total } \\
\hline & & $\mathrm{n}$ & $\%$ & $\mathrm{n}$ & $\%$ & $\mathrm{n}$ & $\%$ \\
\hline \multicolumn{2}{|l|}{ Age - Mean (SD) } & - & $50.78(16.45)$ & - & $55.87(17.20)$ & - & $53.57(17.04)$ \\
\hline \multirow{2}{*}{ Residence } & urban & 93 & 47.9 & 127 & 54.3 & 220 & 51.4 \\
\hline & rural & 101 & 52.1 & 107 & 45.7 & 208 & 48.6 \\
\hline \multirow{2}{*}{ Nature walks } & yes & 73 & 37.6 & 103 & 44.0 & 176 & 41.1 \\
\hline & no & 121 & 62.4 & 131 & 56.0 & 252 & 58.9 \\
\hline \multirow{2}{*}{ Tourism } & yes & 53 & 27.3 & 56 & 23.9 & 109 & 25.5 \\
\hline & no & 141 & 72.7 & 178 & 76.1 & 319 & 74.5 \\
\hline \multirow{2}{*}{ Hunting } & yes & 9 & 4.6 & 2 & 0.9 & 11 & 2.6 \\
\hline & no & 185 & 95.4 & 232 & 99.1 & 417 & 97.4 \\
\hline \multirow{2}{*}{ Fishing } & yes & 12 & 6.2 & 6 & 2.6 & 18 & 4.2 \\
\hline & no & 182 & 93.8 & 228 & 97.4 & 410 & 95.8 \\
\hline \multirow{2}{*}{ Contact with animals } & yes & 89 & 45.9 & 99 & 42.3 & 188 & 43.9 \\
\hline & no & 105 & 54.1 & 135 & 57.7 & 240 & 56.1 \\
\hline \multirow{2}{*}{ Tick bite } & yes & 120 & 61.9 & 128 & 54.7 & 248 & 57.9 \\
\hline & no & 74 & 38.1 & 106 & 45.3 & 180 & 42.1 \\
\hline \multirow{2}{*}{ Consumption of raw milk } & yes & 70 & 36.1 & 67 & 28.6 & 137 & 32.0 \\
\hline & no & 124 & 63.9 & 167 & 71.4 & 291 & 68.0 \\
\hline \multirow{2}{*}{ Cow milk } & yes & 42 & 21.6 & 41 & 17.5 & 83 & 19.4 \\
\hline & no & 152 & 78.4 & 193 & 82.5 & 345 & 80.6 \\
\hline \multirow{2}{*}{ Sheep milk } & yes & 46 & 23.7 & 41 & 17.5 & 87 & 20.3 \\
\hline & no & 148 & 76.3 & 193 & 82.5 & 341 & 79.7 \\
\hline \multirow{2}{*}{ Goat milk } & yes & 24 & 12.4 & 22 & 9.4 & 46 & 10.7 \\
\hline & no & 170 & 87.6 & 212 & 90.6 & 382 & 89.3 \\
\hline \multicolumn{2}{|l|}{ Total number of subjects } & 194 & 45.3 & 234 & 54.7 & 428 & 100.0 \\
\hline
\end{tabular}




\section{Statistical Analysis}

The data were analyzed statistically using IBM SPSS 21.0 statistical program. Demographic data were interpreted by descriptive statistics as averages with standard deviations and as percentages for categorical variables. During the analysis, we used linear regression to interpret the influence between selected variables. For depended variable, we used seroprevalence of $\mathrm{IgG} / \mathrm{IgM}$ antibodies. For independent variable, we use gender, age, residence, nature walks, tourism, hunting, fishing, contact with animals, consumption of raw milk and tick bite. Considered value for statistical significance was $\mathrm{p} \leq 0.05$.

\section{RESULTS}

\section{File Characteristics}

The tested group consisted of 428 persons aged between 12.0 and $93.0 \mathrm{yr}$ (average age $53.57 \mathrm{yr}$, SD 17.04), which included 194 men (45.3\%) with average age $50.78 \mathrm{yr}$, SD 16.45 and 234 women (54.7\%) with average age $55.87 \mathrm{yr}$, SD 17.2. Urban residents created $51.4 \%$ of the sample, $48.6 \%$ subjects resided in rural areas.

According to the questionnaire results, 176 (41.1\%) persons spend their free-time by walking in nature, nature walk, 109

Table 2. Analysis of anti-TBEV antibodies IgG/lgM detected by ELISA ( $N=428)$

\begin{tabular}{|l|c|c|c|c|}
\hline \multirow{2}{*}{} & \multicolumn{2}{|c|}{ IgG } & \multicolumn{2}{c|}{ IgM } \\
\cline { 2 - 5 } & $\mathbf{n}$ & $\%$ & 403 & 94.2 \\
\hline Negative & 415 & 97.0 & 18 & 4.2 \\
\hline Borderline & 8 & 1.9 & 7 & 1.6 \\
\hline Positive & 5 & 1.2 & & $\mathbf{n}$ \\
\hline
\end{tabular}

Table 3. Associations between risk factors and seroprevalence of anti-TBEV antibodies IgM/lgG detected by ELISA

\begin{tabular}{|c|c|c|c|c|}
\hline \multirow[b]{2}{*}{ Risk factors } & \multicolumn{2}{|c|}{ Seroprevalence IgM } & \multicolumn{2}{|c|}{ Seroprevalence IgG } \\
\hline & $\begin{array}{c}\text { B } \\
(95 \% \mathrm{Cl})\end{array}$ & $\mathrm{p}$-value & $\begin{array}{c}\text { B } \\
(95 \% \text { Cl })\end{array}$ & $\mathrm{p}$-value \\
\hline Gender woman/man (ref.) & $\begin{array}{c}0.086 \\
(-0.585-0.756)\end{array}$ & 0.802 & $\begin{array}{c}-2.672 \\
(-11.356-6.617)\end{array}$ & 0.572 \\
\hline Age $\uparrow$ & $\begin{array}{c}-0.003 \\
(-0.23-0.017) \\
\end{array}$ & 0.755 & $\begin{array}{c}0.118 \\
(-0.156-0.391)\end{array}$ & 0.397 \\
\hline Residence rural/urban (ref.) & $\begin{array}{c}-0.577 \\
(-1.242-0.089)\end{array}$ & 0.089 & $\begin{array}{c}-3.601 \\
(-12.871-5.669)\end{array}$ & 0.446 \\
\hline Nature walks yes/no (ref.) & $\begin{array}{c}-0.649 \\
(-1.363-0.065)\end{array}$ & 0.075 & $\begin{array}{c}6.670 \\
(-3.246-16.585)\end{array}$ & 0.187 \\
\hline Tourism yes/no (ref.) & $\begin{array}{c}0.708 \\
(0.034-1.383)\end{array}$ & 0.040 & $\begin{array}{c}-3.241 \\
(-12.637-6.156)\end{array}$ & 0.498 \\
\hline Hunting yes/no (ref.) & $\begin{array}{c}1.619 \\
(-0.464-3.723)\end{array}$ & 0.131 & $\begin{array}{c}110.042 \\
(82.751-137.334)\end{array}$ & $<0.001$ \\
\hline Fishing yes/no (ref.). & $\begin{array}{c}1.701 \\
(0.046-3.356)\end{array}$ & 0.044 & $\begin{array}{c}28.607 \\
(5.720-51.493)\end{array}$ & 0.014 \\
\hline Consumption of raw milk & $\begin{array}{c}0.942 \\
(0.232-1.652)\end{array}$ & 0.009 & $\begin{array}{c}2.521 \\
(-7.392-12.435)\end{array}$ & 0.617 \\
\hline Cow milk & $\begin{array}{c}-0.005 \\
(-0.849-0.839)\end{array}$ & 0.991 & $\begin{array}{c}-3.934 \\
(-15.629-7.761)\end{array}$ & 0.509 \\
\hline Sheep milk & $\begin{array}{c}1.351 \\
(0.531-2.170)\end{array}$ & 0.001 & $\begin{array}{c}7.698 \\
(-3.774-19.170)\end{array}$ & 0.188 \\
\hline Goat milk & $\begin{array}{c}0.244 \\
(-0.834-1.321)\end{array}$ & 0.657 & $\begin{array}{c}2.724 \\
(-12.210-17.658)\end{array}$ & 0.720 \\
\hline Contact with animals yes/no (ref.) & $\begin{array}{c}0.509 \\
(-0.159-1.177)\end{array}$ & 0.135 & $\begin{array}{c}8.341 \\
(-0.873-17.55)\end{array}$ & 0.076 \\
\hline Tick bite yes/no (ref.) & $\begin{array}{c}0.354 \\
(-0.321-1.029)\end{array}$ & 0.303 & $\begin{array}{c}3.366 \\
(-6.0-12.732)\end{array}$ & 0.480 \\
\hline
\end{tabular}

Linear regression, B - linear regression coefficients, $\mathrm{Cl} 95 \%$ - confidence interval, statistically significant values are marked in bold 
(25.5\%) by tourism, $11(2.6 \%)$ by hunting and $18(4.2 \%)$ by fishing. Two hundred and forty-eight (57.9\%) of asked had a history of tick bites and $188(43.9 \%)$ had a history contact with animal. One hundred and thirty-seven (32\%) of asked had a history of consumption of raw milk. The detailed results can be seen in Table 1 .

\section{General Screening}

An ELISA test revealed 415 (97.0\%) negative samples for anti-TBEV IgG, whereas $8(1.9 \%)$ samples were borderline and $5(1.2 \%)$ were positive. The results for IgM were as follows: negative $403(94.2 \%), 18(4.2 \%)$ were borderline and only 7 $(1.6 \%)$ were confirmed as positive results. The detailed results of the detected antibodies prevalence are presented in Table 2.

\section{Association of IgG and IgM Antibodies Prevalence with Gender, Age and Residence}

By gender, age and residence parameters we did not record any statistically significant effect on seroprevalence of $\mathrm{IgM} / \mathrm{IgG}$ class antibodies (Table 3 ).

\section{Association of IgG and IgM Antibodies Prevalence with External Activities}

Results of the linear regression for seroprevalence indicated that tourism (B, 0.708, 95\% CI, 0.034-1.383), fishing (B, 1.701, 95\% CI, 0.046-3.356) were significantly associated with seroprevalence IgM. The analysis revealed a significant association between hunting (B, 110.042, CI 95\%, 82.751-137.334), fishing (B, 28.607, CI 95\%, 5.720-51.493) and seroprevalence IgG. No significant difference in seroprevalence was observed stratified outdoor activities as nature walk (Table 3 ).

\section{Association of IgG and IgM Antibodies Prevalence with Animal Contact Associated to Tick Bite}

No significant difference in seroprevalence was observed for contact with animals and tick bite as a risk factor (Table 3).

\section{Association of IgG and IgM Antibodies Prevalence with Consumption of Raw Milk}

Consumption of raw milk was reported in $32 \%$ of respondents and this factor was significant (B, 0.942, CI 95\%, 0.232-1.652) and consumption of sheep's milk and milk products (B, 1.351, CI 95\%, 0.531-2.170) was also significant for seroprevalence IgM antibodies. No relationship between seroprevalence of consumption of raw cow and goat milk and dairy products was demonstrated (Table 1, 3).

\section{DISCUSSION}

Over the last four decades, TBE has become a growing publichealth challenge in Europe and parts of Asia (9). The aim of this seroepidemiological study was to determine the seroprevalence of TBEV and to reevaluate out the possible risk factors associated with the disease in the selected population group in Slovakia.
After exclusion of participants who reported vaccination against TBEV, Japanese encephalitis or yellow fever $(\mathrm{n}=102)$, 5 of the 428 examined serum samples were positive for IgG TBEV (seroprevalence 1.2\%) and 7 for IgM TBEV (seroprevalence $1.6 \%$ ). Differences between the prevalence of IgG and IgM antibodies can be explained in the acute stage of the disease, mainly by serum screening. The TBEV seroprevalence observed in our study is similar to that reported by French study conducted among forestry workers of northeastern France where ELISA testing confirmed $1.7 \%$ seroprevalence (16).

Many studies conducted on a group of exposed forestry workers shows the presence of antibodies against TBEV: $19.8 \%$ to $81.3 \%$ in eastern Poland $(19,20), 0 \%$ to $5.7 \%$ in Italy $(21,22)$, and $7.3 \%$ in southwestern Germany with variations according to district ranging from $0 \%$ to $43 \%$ (23). In the study conducted by Christova et al., the examined group consist 1,451 residents from all 28 districts in Bulgaria the authors detected $0.6 \%$ of IgG antibodies that shows slightly lower prevalence than in our group (24).

Identification and evaluation of risk factors of TBE is important to understand the risk of contracting TBE in those who travel to industrialized European countries, work in endemic afforested areas and consume of raw milk. Tick habitats are mainly forested and rural areas up to $\sim 1,500 \mathrm{~m}$ of altitude but ticks may also be found in gardens. In Eastern Europe, TBE endemics in urban parks has been described and transmission in Europe is usually limited to the period between April and November $(8,11)$. Human behavior affects TBE incidence, as it can trigger actions that increase the contact of people with infected ticks. One example is nice weather which increases the time spent outdoor activities including: camping, nature walks, biking, fishing, hunting, professional sports and activities of Scouts and Guides (12). Among professional exposure, the highest risk is encountered in woodcutting, forestry, farming, and military activities (7). In our study, we find out up to $41.1 \%$ of nature walks, $25.5 \%$ tourism, $2.6 \%$ hunting, $4.2 \%$ fishing. Significance in a relationship between seroprevalence $\operatorname{IgM}$ and tourism (B, 0.708, 95\% CI, 0.034-1.383), fishing (B, 1.701, $95 \%$ CI, 0.046-3.356) was confirmed. Similar, was confirmed significance in a relationship between seroprevalence IgG and hunting (B, 110.042, CI 95\%, 82.751-137.334) and fishing (B, 28.607, CI 95\% 5.720-51.493). In the study carried on by Blasko-Markic and Socan, high-risk behavior in Slovenia has been shown to include free-time activities, mushroom and berry picking, and farming (13). A recent study in Lithuania carried on by Juceviciene et al. demonstrated that antibodies to TBEV were often in people who frequently spent time in the nature or who had consumed unpasteurized goat's milk (14).

Data from Latvia confirm that people who visit forests (for work, food collection or leisure) are four to five times more likely to encounter ticks than people who do not visit forests (15).

TBE is an acute febrile disease with neurological manifestations and transmitted by ticks and rarely by unpasteurized milk and dairy products (7). The number of cases infected via unpasteurized milk has been estimated to $9 \%$ in Slovakia (17) and $0.9 \%$ in Czech Republic from 1997 to 2008 (18). The Study carried by Cisak et al. found that more than $20 \%$ of goat and sheep milk samples and $11 \%$ of cow milk samples tested were positive for TBEV (4). In our study, we find out that up to $32 \%$ cases of consumption of raw milk is in association with seropositivity 
and it was proven as statistically significant (B, 0.942, CI 95\%, $0.232-1.652$ ). However only consumption of raw sheep's milk was significantly associated with serological status (B, 1.351, CI $95 \%, 0.531-2.170)$.

Anthropomorphic changes in agriculture and the growing popularity of spending free-time in the countryside and outdoor activities influenced the risk of human infection with TBE (6).

As there is no effective treatment for TBE, prevention such as tick infestation control at endemic habitats is only possible option alongside with vaccination, and could be observed in order to prevent infection through a tick bite.

\section{CONCLUSION}

High-risk factors have been confirmed including leisure, tourism, hunting and fishing. Unpasteurized milk and dairy products may also be high risk factor as source of infection, as we confirmed by the statistical significance of antibody seroprevalence. The number of TBE cases caused by consumption of raw milk suggests certain fact that need to be addressed. The threat of infectious diseases due to changing dietary habits, especially the consumption of raw foods, implies the need to better educate consumers about the risks of infection by certain pathogens, including TBEV, in endemic areas. It is important to educate the public through educational campaigns about the diseases and their symptoms, using of protective repellents and appropriate clothing for work in nature and recreation. Considering the present trend of TBEV in the last decade, more clinical case and a higher seroprevalence rate in Slovakia are likely to be expected in the next future.

\section{Acknowledgements}

This work was supported by Grants VEGA No. 1/0198/13, 1/0011/14 of the Ministry of Education, Science, Research and Sport of the Slovak Republic and project VVGS - 3/GSD/2016. We thank also Directory board of University Hospital in Košice for assistance with organization of samples collection at the hospital wards.

\section{Conflict of Interests}

None declared

\section{REFERENCES}

1. Markovinović L, Kosanović Ličina ML, Tešić V, Vojvodić D, Vladušić Lucić I, Kniewald T, et al. An outbreak of tick-borne encephalitis associated with raw goat milk and cheese consumption, Croatia, 2015. Infection. 2016 Oct;44(5):661-5.

2. Amicizia D, Domnich A, Panatto D, Lai PL, Cristina ML, Avio U, et al. Epidemiology of tick-borne encephalitis (TBE) in Europe and its prevention by available vaccines. Hum Vaccin Immunother. 2013 May;9(5):1163-71.

3. Caini S, Szomor K, Ferenczi E, Székelyné Gáspár Á, Csohán Á, Krisztalovics K, et al. Tick-borne encephalitis transmitted by unpasteurized cow milk in western Hungary, September to October 2011. Euro Surveill. 2012 Mar 22;17(12): pii 20128.
4. Cisak E, Wójcik-Fatla A, Zając V, Sroka J, Buczek A, Dutkiewicz J. Prevalence of tick-borne encephalitis virus (TBEV) in samples of raw milk taken randomly from cows, goats and sheep in eastern Poland. Ann Agric Environ Med. 2010;17(2):283-6.

5. Banzhoff A, Bröker M, Zent O. Protection against tick-borne encephalitis (TBE) for people living in and travelling to TBE-endemic areas. Travel Med Infect Dis. 2008 Nov;6(6):331-41.

6. Rieille N, Klaus C, Hoffmann D, Péter O, Voordouw MJ. Goats as sentinel hosts for the detection of tick-borne encephalitis risk areas in the Canton of Valais, Switzerland. BMC Vet Res. 2017 Jul 11;13(1):217. doi: 10.1186/ s12917-017-1136-y.

7. Chrdle A, Chmelík V, Růžek D. Tick-borne encephalitis: what travelers should know when visiting an endemic country. Hum Vaccin Immunother. 2016 Oct 2;12(10):2694-9.

8. Steffen R. Epidemiology of tick-borne encephalitis (TBE) in international travelers to Western/Central Europe and conclusions on vaccination recommendations. J Travel Med. 2016 Apr 17;23(4). pii: taw018.

9. Kunze U; ISW-TBE. Report of the 19th Annual Meeting of the International Scientific Working Group on Tick-Borne Encephalitis (ISW-TBE) - TBE in a changing world. Ticks Tick Borne Dis. 2018 Feb;9(2):146-50.

10. Kríz B, Benes C, Daniel M. Alimentary transmission of tick-borne encephalitis in the Czech Republic (1997-2008). Epidemiol Mikrobiol Imunol. 2009 Apr;58(2):98-103.

11. Rahlenbeck S, Fingerle V, Doggett S. Prevention of tick-borne diseases: an overview. Br J Gen Pract. 2016 Sep;66(650):492-4.

12. Knap N, Avšič-Županc T. Factors affecting the ecology of tick-borne encephalitis in Slovenia. Epidemiol Infect. 2015 Jul;143(10):2059-67.

13. Blasko-Markic M, Socan M. Tick-borne encephalitis in Slovenia: data from a questionnaire survey. Vector Borne Zoonotic Dis. 2012 Jun;12(6):496-502.

14. Juceviciene A, Vapalahti O, Laiskonis A, Čeplikiene J, Leinikki P. Prevalence of tick-borne-encephalitis virus antibodies in Lithuania. J Clin Virol. 2002 Jul;25(1):23-7.

15. Šumilo D, Asokliene L, Avsic-Zupanc T, Bormane A, Vasilenko V, Lucenko I, et al. Behavioral responses to perceived risk of tick-borne encephalitis: vaccination and avoidance in the Baltics and Slovenia. Vaccine. 2008 May 19;26(21):2580-8.

16. Rigaud E, Jaulhac B, Garcia-Bonnet N, Hunfeld KP, Féménia F, Huet $\mathrm{D}$, et al. Seroprevalence of seven pathogens transmitted by the Ixodes ricinus tick in forestry workers in France. Clin Microbiol Infect. 2016 Aug;22(8):735.e1-9. doi: 10.1016/j.cmi.2016.05.014.

17. Labuda M, Elecková E, Licková M, Sabó A. Tick-borne encephalitis virus foci in Slovakia. Int J Med Microbiol. 2002 Jun;291 Suppl 33:43-7.

18. Kríz B, Benes C, Daniel M. Alimentary transmission of tick-borne encephalitis in the Czech Republic (1997-2008). Epidemiol Mikrobiol Imunol. 2009 Apr;58(2):98-103.

19. Cisak E, Sroka J, Zwoliński J, Umiński J. Seroepidemiologic study on tickborne encephalitis among forestry workers and farmers from the Lublin region (eastern Poland). Ann Agric Environ Med.1998;5(2):177-81.

20. Siennicka J, Trzcińska A, Gut W. Immunity against tick borne encephalitis virus (TBE) in population of forest workers in Bialowieza. Przegl Epidemiol. 2010;64(2):303-5. (In Polish)

21. Di Renzi S, Martini A, Binazzi A, Marinaccio A, Vonesch N, D’Amico $\mathrm{W}$, et al. Risk of acquiring tick-borne infections in forestry workers from Lazio, Italy. Eur J Clin Microbiol Infect Dis. 2010 Dec;29(12):1579-81.

22. Pugliese A, Beltramo T, Torre D. Seroprevalence study of Tick-borne encephalitis, Borrelia burgdorferi, Dengue and Toscana virus in Turin Province. Cell Biochem Funct. 2007 Mar-Apr;25(2):185-8.

23. Oehme R, Hartelt K, Backe H, Brockmann S, Kimmig P. Foci of tickborne diseases in southwest Germany. Int J Med Microbiol. 2002 Jun;291 Suppl 33:22-9.

24. Christova I, Panayotova E, Tchakarova S, Taseva E, Trifonova I, Gladnishka T. A nationwide seroprevalence screening for West Nile virus and Tick-borne encephalitis virus in the population of Bulgaria. J MedVirol. 2017 Oct;89(10):1875-8. 